\title{
Studies on the Thermal, Mechanical and Chemical Resistance Properties of Natural Resource Derived Polymers
}

\author{
Shrawan Kumar Shukla ${ }^{a}$, Kavita Srivastava ${ }^{b}$, Deepak Srivastava ${ }^{a *}$ \\ ${ }^{a}$ Department of Plastic Technology, Harcourt Butler Technological Institute, Kanpur, 208002, India \\ ${ }^{b}$ Department of Chemistry, Vikramajit Singh Sanatan Dharma College - V. S. S. D. College, \\ Kanpur, 208002, India
}

Received: July 24, 2015; Revised: August 29, 2015

\begin{abstract}
Cardanol-based epoxidized resole resins $(E R C F)$ were synthesized by reacting resole type phenolic resin $(R C F)$ and epichlorohydrin in basic medium, at $120^{\circ} \mathrm{C}$. Resole type phenolic resins were synthesized by reacting cardanol $(C)$ and formaldehyde $(F)$ in the presence of sodium hydroxide, as catalyst, at five different temperatures ranging between $60-80^{\circ} \mathrm{C}$ with an interval of $5^{\circ} \mathrm{C}$ for a maximum period of $6 \mathrm{~h}$. These prepared samples were cured using $15 \%$ polyamide as curing agent at $120 \pm 2$ ${ }^{\circ} \mathrm{C}$ for $1 \mathrm{~h}$. Mechanical and chemical resistance characteristics of prepared samples were evaluated to assess the possibility of using such thermosetting resins as a new eco-friendly material for engineering applications. Upon evaluation, it was found that the prepared resins systems exhibit better properties compared to commercial epoxy resin in term of increase in tensile strength, elongation-at-break and impact strength, of castings and gloss, scratch hardness, adhesion and flexibility of the films. The anticorrosive properties from chemical resistance of the prepared resin systems are found to be superior than unmodified epoxy resins. The TG/DTG thermograms showed two step decomposition behaviors in all the prepared samples.
\end{abstract}

Keywords: cardanol, resole resin, epoxy resin, tensile strength, scratch hardness, thermal stability

\section{Introduction}

With continuous depletion of petrochemical feedstock and their rising prices, the chemical industry is now looking for alternative renewable and sustainable materials. It is essential to plan substitution of these materials with environmentally friendly materials and this can be classified as non renewable ones, known since a long time. Cardanol derived from cashew nut shell liquid (CNSL) has reactive phenolic group and aliphatic double bonds that could produce novel functional materials for polymer and coating applications. Resole type phenolic resins were prepared using phenol and formaldehyde under basic environment in a step growth polymerization process $^{1}$. These are very highly cross linked materials and have a wide range of commercial applications such as molding compounds, coatings, and binders etc.,3. The molecular structure of these resins depend on the ratio of formaldehyde to phenol, temperature, $\mathrm{pH}$, etc. The resole resins synthesis are halted when the appropriate degree of condensation in the resin (viscosity) have been achieved. These are usually polymerized with molar excess of formaldehyde and the resin contains methylene and dimethylene ether bridges and methylol groups ${ }^{4-6}$. The ease of synthesis, attractive cost factor, excellent track, good thermal stability, char yielding properties, and ablative characteristics are some of the features responsible for their dominance in the field. They are characterized by additional dimethylene ether bridges and remaining methylol groups in the ortho and para positions of the phenolic rings ${ }^{7,8}$.

*e-mail: dsri92@gmail.com
Cardanol is isolated from cashew nut shells by vacuum distillation. Utilization of CNSL in polymer chemistry has been well experimented and commercialized ${ }^{9}$. These new cardanol based resole resin are prepared to replace traditional resole that are used in applications as diverse as industrial and commercial, because of their excellent ablative properties and structural integrity. Long chain phenols contained in cardanol, serves as a natural and renewable sources to fine chemical products, such as solvents, varnishes, surfactants, and plasticizers, and also are well known in coating and resin industries. These are also used as high temperature polymers ${ }^{10-13}$. These prepared resole resins may further be modified by epoxidation with epichlorohydrin to duplicate the performance of such phenolic resoles.

Epoxy resins are one of the most important classes of thermosetting polymer having several outstanding characteristics ${ }^{14}$. These epoxy resins are industrially very important polymeric materials and these are used in the formulation of electronic materials, adhesives, coatings and structural application due to their excellent attributes such as chemical resistance, dielectric and insulating properties ${ }^{15-17}$. These epoxy polymers display interesting advantages by perticulary the use of renewable resources in order to synthesize bio-based chemicals and products ${ }^{18}$.

In the present work, it has been synthesized cardanol-based epoxidized resole resin and evaluated their mechanical, thermal, and chemical properties. 


\section{Experimental}

\subsection{Materials}

Cardanol (M/s Dheer Gramoudyog Ltd. Kanpur), Formaldehyde (37\% wt solution from M/s Qualikem Industries, New Delhi), sulphuric acid obtained from M/s E. Merck, New Delhi. Sodium hydroxide (M/s CDH Pvt. Ltd, New Delhi), epicholorohydrin (M/s Ranbaxy Laboratories Ltd. Punjab), Polyamide (amine value 200-400 mg KOH/g, M/s Thomas Baker Pvt. Ltd., Mumbai) were used during synthesis.

\subsection{Synthesis of cardanol-based epoxidized resole resin}

The resole-type phenolic resins were synthesized by reacting cardanol $(C)$ and formaldehyde $(F)$ in the presence of sodium hydroxide as a catalyst. The synthesis of these resins was carried out in a high temperature oil bath (Model PT-266,) (Figure 1), laboratory glass reactor equipped with a stirrer, thermometer and reflux condenser. The reaction mixture of cardanol and $37 \%$ wt formaldehyde was taken into R.B. flask and heated upto a temperature of $40{ }^{\circ} \mathrm{C}$. After complete addition, the temperature of reaction kettle was maintained to $60{ }^{\circ} \mathrm{C}$ and the $\mathrm{pH}$ was maintained between $7-8$ by the addition of $10 \%$ wt sulphuric acid solution in the mixture of $C$ and $F$. The resole-type phenolic resin synthesized by aforesaid method was further epoxidized by the addition of excess of epicholorohydrin (more than six times for complete epoxidation) at temperature of $60{ }^{\circ} \mathrm{C}$ with continuous stirring along with $40 \%$ aq. $\mathrm{NaOH}$, added drop wise continuously. After addition, the temperature of the reaction mixture was raised to $120^{\circ} \mathrm{C}$. Five samples of cardanol-based epoxidized resole resins were prepared and are designated as per Table 1. The extent of epoxidation was measured which was found to be in the range $0.81-0.93$ as given in Table 1.

\subsection{Preparation of castings and films}

The prepared cardanol-based epoxidized resole resin was mixed with $15 \mathrm{wt} \%$ polyamide as a curing agent. The mixture of cardanol-based epoxidized resole resins and curing agent was taken in small glass vials and mixed uniformly with the help of glass rod at room temperature. Thereafter, glass vials were kept in pre heated air oven at $120^{\circ} \mathrm{C}$ for a period of $1 \mathrm{~h}$. The tin and glass panels were used subjected to difference performance test.

The samples of cardanol-based epoxidized resole resins were prepared by casting in a self- designed iron mould. The mould was kept in pre heated air oven at $120^{\circ} \mathrm{C}$ for the curing of samples.

The films of cardanol-based epoxidized resole resins were applied on the steel and glass panels of the size of $150 \times 50 \times 1.25 \mathrm{~mm}$ for the evaluation of mechanical and chemical resistance to water, acid, alkalis and solvents. The panels were prepared by applying the films of resin samples by using Bird film applicator (M/s Khushboo Scientific Ltd., Mumbai, India). The dry film thickness of about 100 microns was maintained on all the panels. These films were then cured as per the curing schedule obtained from DSC $\left(85^{\circ} \pm 1{ }^{\circ} \mathrm{C} / 90 \mathrm{~min}\right)$.

\subsection{Mechanical properties}

Dumb-bell shaped samples were prepared and were used for the determination of tensile strength and elongation-at-break as per ASTM specification ASTM-D638 ${ }^{19}$. For each mole ratio five specimens were prepared for the calculating tensile strength was measured.

Both ends of samples were tightened in metallic grips of Universal testing machine (UTM) (Figure 2). The cross-head speed was kept at $25 \mathrm{~mm}$ per minute. The tensile strength and percentage elongation-at-break of castings of cured

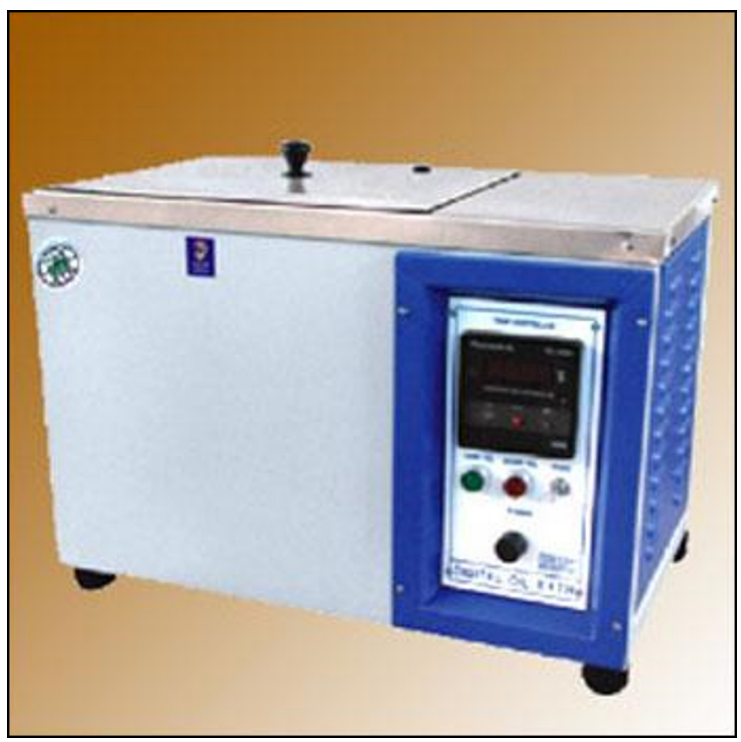

Figure 1. High Temperature Oil Bath.

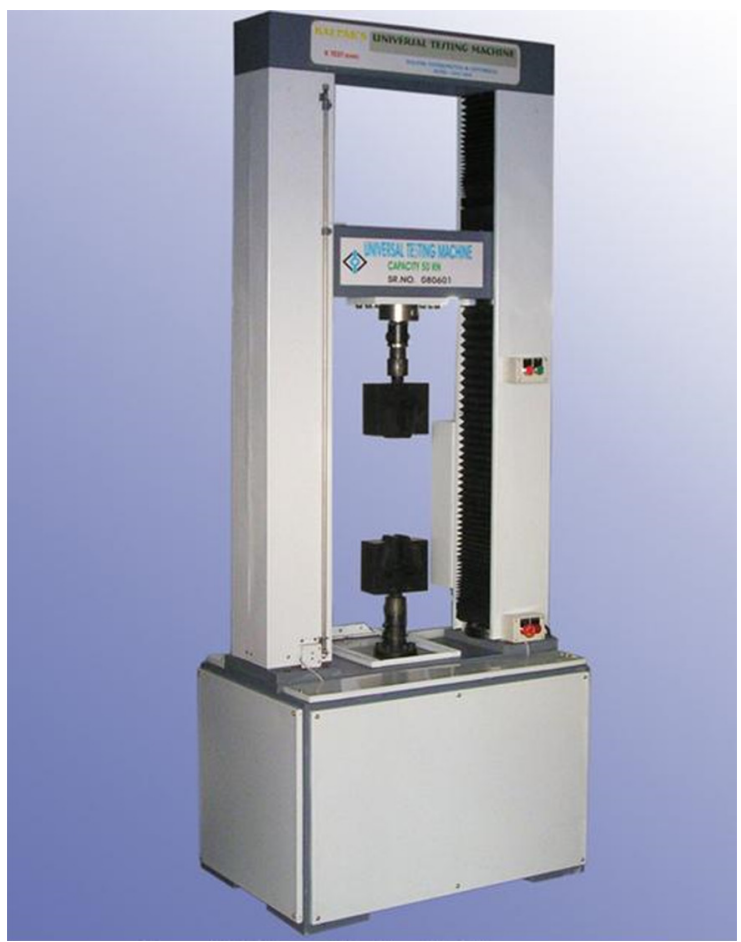

Figure 2. Universal Testing Machine. 
Table 1. Sample designation and epoxy equivalent weight.

\begin{tabular}{|c|c|c|c|c|c|c|}
\hline \multirow{2}{*}{ S.N. } & \multirow{2}{*}{$\begin{array}{c}\text { Cardanol } \\
\text { (mole) }\end{array}$} & \multirow{2}{*}{$\begin{array}{l}\text { Formaldehyde } \\
\text { (mole) }\end{array}$} & \multirow{2}{*}{$\begin{array}{l}\text { Sample code of } \\
\text { corresponding } \\
\text { epoxidized } \\
\text { resole }\end{array}$} & \multicolumn{2}{|c|}{ EEW } & \multirow{2}{*}{$\begin{array}{c}\text { Degree of } \\
\text { epoxidation } \\
\text { B/A }\end{array}$} \\
\hline & & & & Actual (A) & Expected (B) & \\
\hline 1 & 1 & 1.2 & $\mathrm{ERCF}_{112}$ & 486 & 402 & 0.82 \\
\hline 2 & 1 & 1.4 & $\mathrm{ERCF}_{114}$ & 460 & 430 & 0.93 \\
\hline 3 & 1 & 1.6 & $\mathrm{ERCF}_{116}$ & 490 & 398 & 0.81 \\
\hline 4 & 1 & 1.8 & $\mathrm{ERCF}_{118}$ & 532 & 498 & 0.93 \\
\hline 5 & 1 & 2.0 & $\mathrm{ERCF}_{120}$ & 465 & 410 & 0.88 \\
\hline
\end{tabular}

cardanol-based epoxidized resole resin samples were measured UTM (M/s Khushboo Scientific Ltd., Mumbai, India).

Notched rectangular samples were used for determining the impact strength with the help of a pendulum Izod impact tester. The test specimens were cut from the cured block according to ASTM standard D256 ${ }^{20}$. The size of specimens are $63.5 \times 12.7 \times 45.72 \mathrm{~mm}$ with a recommended notch depth of $2.54 \mathrm{~mm}$. The test specimen clamped into position so that the notched end of specimen edge of pendulum. Now, the pendulum hammer released, allowed strike the specimen, and swing through. If the specimen does not break, more weights are attached to the hammer and test is repeated until failure is observed. The impact strength was read directly in fit-lbf from the scale.

The scratch hardness of the cured film of cardanol-based epoxidized resole resins was evaluated as per IS: 101-199021. The test was performed by "Automatic Hardness Tester" (M/s Khushboo Scientific Ltd., Mumbai, India). In this test, a hard hemisphere needle of the diameter of $1 \mathrm{~mm}$ was allowed to run on the test panel at the rate of $30-40 \mathrm{~mm} \mathrm{~s}^{-1}$. A specified load was placed on the top of needle and the panel was examined for sign of bare metal.

The impact resistance of the cured film of cardanol-based epoxidized resole resins was evaluated as per IS: $101-1990^{21}$. The tests were performed by "Tubular Impact hardness Tester" (M/s Khushboo Scientific Ltd., Mumbai, India). The apparatus consisted of a steel block $(500 \mathrm{~g})$ which sides vertically between two guides. This was mounted under the block, commonly known as the tool holder, where it was fixed as the indenter. The block and tool were allowed to fall under gravity onto the die blocks with a hole in centre. The test panel between the die blocks was impacted by tool. The depth of indentation was varied by inserting washer of known thickness between indenter and tool holder. The failure of coatings film was shown by cracking by the loss of adhesion at the deformed portions of the test panels.

The adhesion and flexibility of the cured film of cardanol-based epoxidized resole resins were evaluated as per IS: 101-199021. The test was performed on "Mandrel" (M/s Khushboo Scientific Ltd., Mumbai, India). In this test, the panel was passed through a cylindrical bar of different diameters. At specified cylindrical bar, the panel was examined for sign of cracking, flaking and detachment from the substrate, after the sample had been bent through $180^{\circ} \mathrm{C}$.

The gloss of the cured film of cardanol-based epoxidized resole resins was evaluated as per IS: 101-1990 standards $^{21}$. The test was performed on triglossometer (M/s Khushboo Scientific Ltd., Mumbai, India) by watching the films from $60^{\circ}$ angle for gloss. Initially, the instrument was standardized with the supplied standard sample from the company.

\subsection{Thermal properties}

The percent weight loss and thermal degradation characteristics of prepared samples were evaluated by thermogravimetric analyzer (TGA) recorded on Perkin-Elmer (Model Pyris 1 TGA, Switzerland) control unit. The dynamic thermo grams between temperature and weight loss were recorded by using plotter attached with the instrument. A preweighted sample was put on the pan which was placed on the thermal balance of the instrument at a heating rate of $20^{\circ} \mathrm{C} \mathrm{min}^{-1}$ in nitrogen atmosphere, the sample was run in the temperature range of 50-600 ${ }^{\circ} \mathrm{C}$. The stability of epoxy samples was determined by a comparison of the onset degradation temperature (up to $5 \%$ weight loss) of cured samples.

\subsection{Chemical resistance}

The prepared glass panels, as per procedure given in section 2.3 of this article, such as mild steel panel, tin plate panel and glass panels (as per IS-101, 1964) were used to evaluated for their chemical properties. The panels were prepared by applying the films of resin samples by using Bird film applicator (M/s Khushboo Scientific Ltd., Mumbai, India). The dry film thickness of about 100 microns of cardanol based epoxidized resole resin on glass panels of the size $150 \times 50 \times 1.25 \mathrm{~mm}$ for evaluation of resistance to water, acids, alkalies and solvents.

\section{Results and Discussion}

\subsection{Tensile strength, elongation-at-break and impact strength of cardanol-based epoxidized resole resin}

The variation of tensile strength, elongation-at-break and impact strength in the casting of cardanol-based epoxidized resole resins containing varying molar ratios cured with polyamide has been given in Table 2 .

A gradual increase in tensile strength was noted as the concentration of the formaldehyde was increased as the molar ratio increased from $1: 1.2$ to $1: 2.0$. An increase in tensile strength might be attributed to the increase in crosslink density due to interaction between curing agent and epoxy resin, which might have been mechanically stronger than commercial epoxy resin system in ranging between $31-37 \mathrm{MPa}^{[22]}$. The $\Delta H$ values related to the cure process were determined from the area of the exotherm peak obtained from DSC analysis 
taken in dynamic mode, which were found in the range of 33.91 - $94.00 \mathrm{Jmol}^{-1}$. Sample with higher concentration of formaldehyde viz. $E R C F_{120}$ was found to show maximum elongation-at-break amongst all other samples. A higher elongation might be due to the result of straightening of entangled chains of cardanol- based epoxidized resole resin. the prepared resin sample with highest molar ratio $\left(E R C F_{120}\right)$ was found to show increased impact strength which indicate the absorption of greater impact energies. The properties of casting of all cured samples of cardanol- based epoxidized resole resin samples revealed that the $E R C F_{120}$ was found to be exhibit increased tensile and impact strength and higher elongation-at-break of all samples. The chemical structure of cardanol-based epoxidized resole resin has been proposed as in Scheme 1 and epoxidation reaction mechanism has been given in Scheme 2 .

\subsection{Scratch hardness, adhesion, flexibility, gloss, impact resistance of cardanol-based epoxidized resole resin}

Table 2 showed the surface and mechanical properties of the cured films of the cardanol-based epoxidized resole resins. All the cured films showed over all good performance. The scratch hardness was found to be in the range 900-1500g. All the coatings on mild steel panels passed the scratch performance test up to $1.5 \mathrm{~kg}$ load. As the concentration of formaldehyde increased, the scratch hardness of the cured films of cardanol-based epoxidized resole resins was found to be also increased. The films of all prepared samples passed
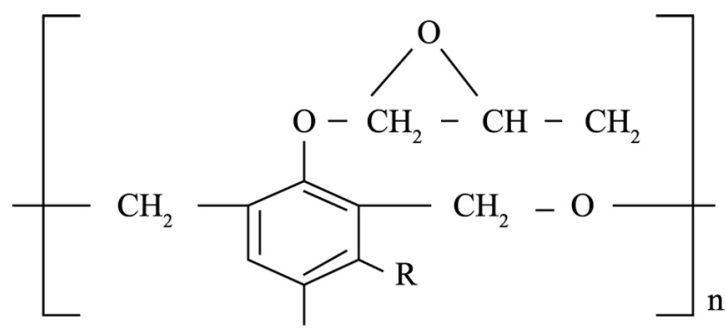

Scheme 1. Chemical structure of cardanol-based epoxidised resole resin. the bend test indicating good flexibility. The films showed no sign of damage, detachment, cracking or removal of coating during and after test ${ }^{23}$. This is primarily due to the long aliphatic carbon-carbon chain in the cardanol molecule which balances the rigid and hard nature of cured films by incorporating this chain in crosslinked structure. All the prepared resin samples exhibited better impact resistance as compared to the impact resistance of commercial epoxy resin. The gloss of all films was found to be excellent.

\subsection{Thermogravimetric Analysis (TGA)}

TGA is one of the most widely used techniques for measuring the thermal stability of polymeric samples. In this technique, the rate of weight loss is measured as a function of a programmed rate of increase in temperature. Thermal stability of cross-linked networks plays an important role and is greatly influenced by structure and chemical decomposition ${ }^{24,25}$. The thermogravimetric (TG) trace for sample $E R C F_{112}$ is shown in Figure 3. From the scan, the temperature of onset $\left(T_{0}\right)$, peak temperature $\left(T_{P}\right)$, and the temperature of completion $\left(T_{F}\right)$ were noted and tabulated in Table 3. Initial degradation temperature (IDT) was considered after 3-5\% weight loss as in the initial stages impurities and moisture present in the system decomposes first It is clearly indicated, from the results (Table 3 ), that the sample showed two-step mass loss in TG traces and

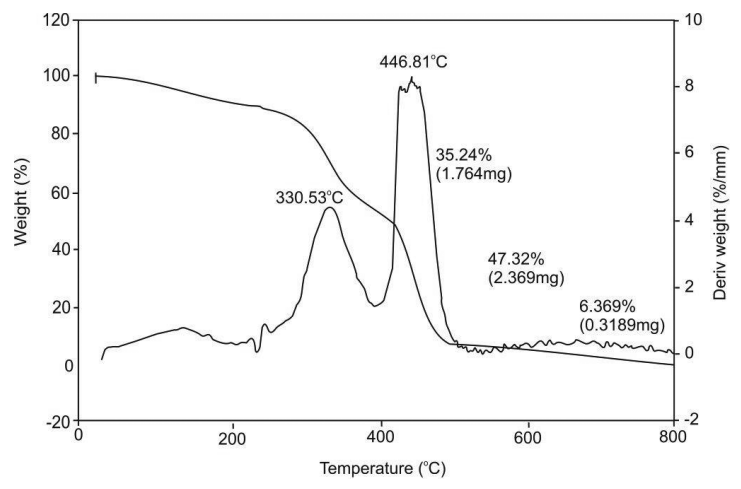

Figure 3. TGA scan of epoxidized resole resin.<smiles>[R]c1cccc(COCC(O)C([R])CCl)c1</smiles><smiles>[R]c1cccc(OCC(C)OC)c1</smiles>

Scheme 2. Epoxidation of cardanol-based resole resin. 
Table 2. Mechanical Properties of cardanol- based epoxidized resole resin.

\begin{tabular}{cccccccc}
\hline \multirow{2}{*}{$\begin{array}{c}\text { Sample } \\
\text { code }\end{array}$} & $\begin{array}{c}\text { Tensile } \\
\text { Strength } \\
\mathbf{( M P a )}\end{array}$ & $\begin{array}{c}\text { Impact } \\
\text { Strength } \\
\mathbf{( K J / \mathbf { m } ^ { 2 } )}\end{array}$ & $\begin{array}{c}\text { Elongation } \\
\text { at - Break } \mathbf{( \% )}\end{array}$ & $\begin{array}{c}\text { Gloss } \\
\left(\mathbf{6 0}^{\mathbf{0}} \text { angle) }\right.\end{array}$ & $\begin{array}{c}\text { Scratch } \\
\text { hardness } \\
\mathbf{( K g )}\end{array}$ & $\begin{array}{c}\text { Adhesion \& } \\
\text { Flexibility }\end{array}$ & $\begin{array}{c}\text { Impact } \\
\text { resistance } \\
(\mathbf{K g} \mathbf{~ c m})\end{array}$ \\
\hline $\mathrm{ERCF}_{112}$ & $60.3 \pm 1.5$ & $21.8 \pm 0.15$ & $13.1 \pm 0.10$ & $95.2 \pm 0.33$ & $0.9 \pm 0.08$ & Pass & $50 \pm 18$ \\
$\mathrm{ERCF}_{114}$ & $64.2 \pm 1.6$ & $19.6 \pm 0.62$ & $12.2 \pm 0.11$ & $96.7 \pm 0.66$ & $1.1 \pm 0.04$ & Pass & $55 \pm 17$ \\
$\mathrm{ERCF}_{116}$ & $67.8 \pm 1.3$ & $18.9 \pm 0.09$ & $11.9 \pm 0.17$ & $95.8 \pm 0.20$ & $1.2 \pm 0.08$ & Pass & $65 \pm 19$ \\
$\mathrm{ERCF}_{118}$ & $71.5 \pm 1.4$ & $17.3 \pm 0.05$ & $11.1 \pm 0.09$ & $97.3 \pm 0.44$ & $1.4 \pm 0.11$ & Pass & $70 \pm 22$ \\
$\mathrm{ERCF}_{120}$ & $77.4 \pm 1.2$ & $16.7 \pm 0.10$ & $10.1 \pm 0.32$ & $98.4 \pm 0.34$ & $1.5 \pm 0.09$ & Pass & $75 \pm 22$ \\
\hline
\end{tabular}

Table 3. Thermal Behavior of isothermally cured sample.

\begin{tabular}{|c|c|c|c|c|c|c|c|c|c|c|}
\hline \multirow{2}{*}{ S.N. } & \multirow{2}{*}{ Sample } & $\mathbf{T}_{\mathbf{i}}$ & $\mathbf{T}_{\mathrm{p}}$ & $\mathbf{T}_{\mathrm{f}}$ & \multirow{2}{*}{$\begin{array}{c}\text { Mass } \\
\text { Loss }(\%)\end{array}$} & $\mathbf{T}_{\mathbf{i}}$ & $T_{p}$ & $\mathbf{T}_{\mathrm{f}}$ & \multirow{2}{*}{$\begin{array}{c}\text { Mass } \\
\text { Loss }(\%)\end{array}$} & \multirow{2}{*}{$\begin{array}{c}\text { Char } \\
\text { Yield } \\
(\%)\end{array}$} \\
\hline & & & I stage & & & & II stage & & & \\
\hline 1 & ERCF $_{112}$ & 250 & 315.51 & 305 & 41.53 & 310 & 445.32 & 520 & 53.18 & 4.78 \\
\hline 2 & $\mathrm{ERCF}_{114}$ & 240 & 315.54 & 370 & 43.46 & 370 & 450.14 & 520 & 51.99 & 3.42 \\
\hline 3 & $\mathrm{ERCF}_{116}$ & 190 & 320.70 & 390 & 42.77 & 390 & 449.07 & 530 & 48.01 & 10.22 \\
\hline 4 & $\mathrm{ERCF}_{118}$ & 230 & 325.30 & 395 & 45.46 & 395 & 447.81 & 545 & 47.82 & 7.32 \\
\hline 5 & ERCF $_{120}$ & 245 & 335.90 & 345 & 48.19 & 345 & 451.35 & 510 & 49.98 & 5.83 \\
\hline
\end{tabular}

the shoulders observed in DTG traces indicated a two-step thermal degradation process.

The first oxidative degradation was in between $200-450^{\circ} \mathrm{C}$ and second degradation started at a temperature of around $450{ }^{\circ} \mathrm{C}$. The improved resistance of thermo-oxidative degradation might be due to the participation of the aromatic groups of cardanol in the decomposition reaction ${ }^{26}$. Lin \& $\mathrm{Ma}^{27}$ studied that as the temperature increased the strength of the $\mathrm{C}-\mathrm{H}$ bond of aliphatic bridge decreased, and this indicated the cleavage of the methylene bridges. The aromatic content would give higher thermal stability in prepared cardanol-based epoxidized resole resin.

\subsection{Chemical resistance}

The comparative acid and alkali test (refer Figures 4-5) evaluated for twelve months immersion in different concentration of acid and alkali solutions, showed improvement in the performance as the formaldehyde content was increased. It was seen from the results as the concentration of acid and alkali solutions increased, the resistance of cured films were slightly decreased (Figures 4-5). The cured film of samples $E R C F_{118}$ and $E R C F_{120}$ showed better resistance as compared to $E R C F_{112}, E R C F_{114}$ and $E R C F_{116}$. The higher concentration of alkali solution less affected the film surface lower than alkali resistance.

The comparative resistance of cured films of different epoxy samples against different solvents and they reveals almost same behavior as shown with acids and alkalies. It could be also seen from Figure 6 that cured film surface was strongly affected by solvents like methanol and acetone whereas the cured films retained their surface in solvents like toluene and xylene for a period of twelve months.

It is clearly indicated from the results, that the coating films of prepared resin system offered improvement towards resistance to water, solvents, specified concentration of acids and alkalis due to overall balanced chemical backbone.

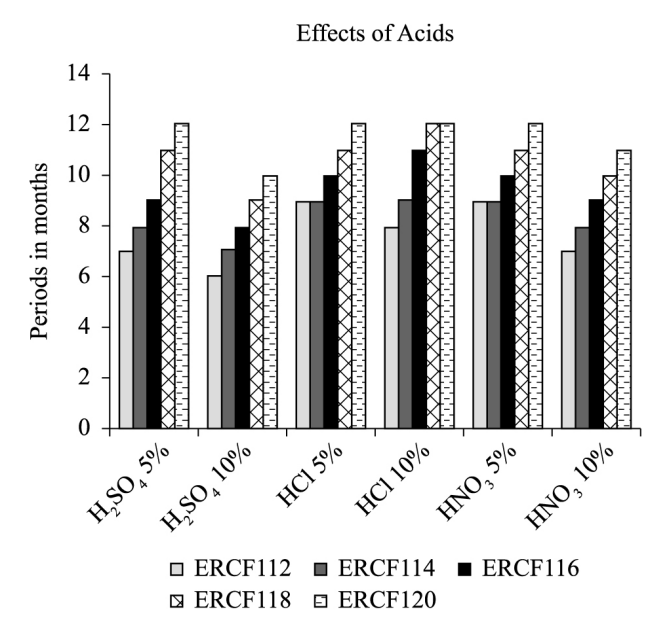

Figure 4. Graph of effects of Acids in epoxidized resole resin.

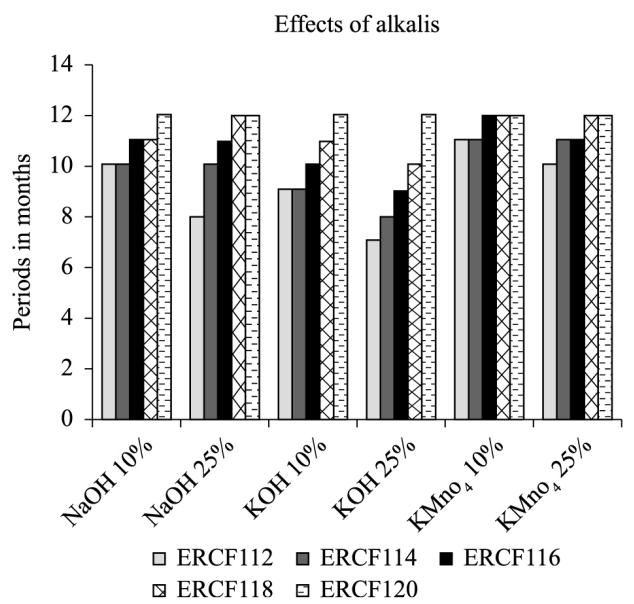

Figure 5. Graph of effects of alkalis in epoxidized resole resin. 


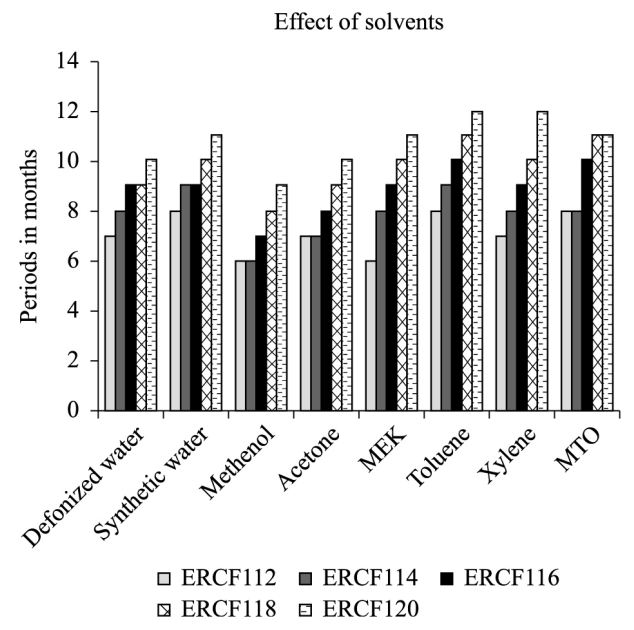

Figure 6. Graph of effects of solvents in epoxidized resole resin.

This behavior could be attributed to the reaction of cross linking agent with epoxide and hydroxyl groups which were relatively stable bonds, resulting in high chemical and solvent resistant film ${ }^{28,29}$.

\section{References}

1. Żmihorska-Gotfryd AZ. Coating compositions based on phenol-formaldehyde resin and urathane prepolymers. Progress in Organic Coatings. 2004; 49(2):109-114. http://dx.doi. org/10.1016/j.porgcoat.2003.09.002.

2. Airebe GA, Echeverria JM, Martyn MD, Etxeberria AM and Mondragon I. Influence of the initial formaldehyde to molar ratio (f/p) on the formation of a phenolic resole resin catalyst with amine. Polymer. 2000; 41(18):6797-6802. http://dx.doi. org/10.1016/S0032-3861(00)00044-6.

3. Lei Y, Wu Q and Lian K. Cure kinetics of aqueous phenolformaldehyde resins used for oriented stanboard manufacturing: analytical technique. Journal of Applied Polymer Science. 2006; 100(2):1642-1650. http://dx.doi.org/10.1002/app.23756.

4. Monni J, Alvila L and Pakkanen TT. Structural and physical changes in phenolformaldehyde resol resin, as a function of the degree of condensation of resol solution. Industrial \& Engineering Chemistry Research. 2007; 46(21):6916-6924. http://dx.doi.org/10.1021/ie070297a.

5. Alonso MV, Oliet M, Garcia J, Rodriguez F and Echeverría J. Gelation and isoconversional kinetic analysis of lignin-phenolformaldehyde resin cure. Chemical Engineering Journal. 2006; 122(3):159-166. http://dx.doi.org/10.1016/j.cej.2006.06.008.

6. Helle H, Välimäki H and Lekkala J. Comparing a $10 \mathrm{MHz}$ thickness-shear mode quartz resonator with a commercial process viscometer in monitoring resol manufacture process. Sensors and Actuators. B, Chemical. 2002; 81(2-3):133-140. http://dx.doi.org/10.1016/S0925-4005(01)00943-1.

7. Lee YK, Kim DJ, Kim HJ, Hwang TS, Rafailovich M and Sokolov J. Activation energy and curing behavior of resol- and novolac-typephenolic resins by differentialscanning calorimetry and thermogravimetric analysis. Journal of Applied Polymer Science. 2003; 89(10):2589-2596. http://dx.doi.org/10.1002/ app. 12340 .

8. Niimura N and Miyakoshi T. Structural characterization of cashew resin film using twostage pyrolysis-gas chromatography/ mass spectrometry. International Journal of Polymer Analysis

\section{Conclusion}

From the results it can be concluded that modification of cardanol-based resole resin via modification has resulted into improvement in their properties. As the increase in concentration of formaldehyde, the tensile strength of prepared resin increased whereas the percent elongation-at-break of the prepared samples decreased. The increase in formaldehyde content in epoxy resin increased the values of scratch hardness and impact resistance whereas all the samples passed through adhesion and flexibility tests. This showed good mechanical properties of coating film of prepared epoxy samples. The films showed no sign of damage, detachment, cracking or removal of coating. From TGA results, the sample showed two-step mass loss in TG traces and two-step thermal degradation process. The chemical resistance of cured films of epoxy resin showed good resistance to acids, alkalis and solvents. Therefore, this work provides a new way of utilizing renewable resource materials to prepare cost-effective and eco-friendly bio-based epoxy resole resin with high performance for coating applications. Such work has never been reported by other workers in the field as revealed from the literature.

and Characterization. 2003; 8(1):47-66. http://dx.doi. org/10.1080/10236660304886.

9. Gopalakrishnan S and Sujatha R. Synthesis and thermal properties of polyurathanes from cardanol-furfural resin. Journal of Chemical and Pharmaceutical Research. 2010; 2:193-205.

10. Li S, Yang X, Huang K, Li M and Xia J. Design, preparation and properties of novel renewable UV-curablecopolymers based on cardanol and dimer fatty acids. Progress in Organic Coatings. 2014; 77(2):388-394. http://dx.doi.org/10.1016/j. porgcoat.2013.11.011.

11. Biswas BK, Biswas S, Khan M and Chandraray B. Preparation and characterization of CNSL modified phenol-formaldehyde resin. Journal of Polymer Materials. 2009; 26(1):7-15.

12. Nguyen LH, Nguyen DT, La TH, Phan KX, Nguyen TTT and Nguyen HN. Effects of nanoclay on the properties of cardanolmodified-resol-epoxy-novolac composite materials. Journal of Applied Polymer Science. 2007; 103(5):3238-3242. http:// dx.doi.org/10.1002/app.24976.

13. Dominguez JC, Oliet M, Alonso MV, Rojo E and Rodriguez F. Structural, thermal and rheological behavior of a bio-based phenolic resin in relation to a commercial resol resin. Industrial Crops and Products. 2013; 42:308-314. http://dx.doi.org/10.1016/j. indcrop.2012.06.004.

14. Lahlali D, Naffakh M and Dumon M. Cure kinetics and modeling of an epoxy resin crosslinked in the presence of two different diamine hardeners. Polymer Engineering and Science. 2005; 45(12):1581-1589. http://dx.doi.org/10.1002/pen.20274.

15. Chen W, Wang Y and Chang F. Study on the curing kinetics and curing mechanism of epoxy resin based on diglycidyl ether of bisphenol-A and melamine phosphate. Journal of Applied Polymer Science. 2004; 92(2):892-900. http://dx.doi. org/10.1002/app.20054.

16. Gu A and Liang G. Thermal stability and kinetics analysis of rubber-modified epoxy resins by high-resolution thermogravimetric analysis. Journal of Applied Polymer Science. 2003; 89(13):35943600. http://dx.doi.org/10.1002/app.12786. 
17. Benyahya S, Aouf C, Caillol S, Boutevin B, Pascault JP and Fulcrand H. Functionalized green tea tannins as phenolic prepolymers for bio-based epoxy resins. Industrial Crops and Products. 2014; 53:296-307. http://dx.doi.org/10.1016/j. indcrop.2013.12.045.

18. Tao Z, Yang S, Chen J and Fan L. Synthesis and characterization of imide ring and silioxane-containing cycloaliphatic epoxy resin. European Polymer Journal. 2007; 43(4):1470-1479. http://dx.doi.org/10.1016/j.eurpolymj.2007.01.039.

19. American Society for Testing and Materials - ASTM. ASTM D638-14: standard test method for tensile properties of plastics. West Conshohocken: ASTM International; 2014.

20. American Society for Testing and Materials - ASTM. ASTM D256-10: standard test methods for determining the izod pendulum impact resistance of plastics. West Conshohocken: ASTM International; 2010.

21. Bureau of Indian Standards. IS-101: 1990: methods of sampling and test for paints, varnishes and related products. New Delhi; 2008.

22. Takeichi T. Epoxy resins and phenol-formaldehyde resins. Polymer Science: A Comprehensive Reference. 2012; 5:723751. http://dx.doi.org/10.1016/b978-0-444-53349-4.00157-6.

23. Bajpai M, Shukla V and Kumar A. Film performance and curing of epoxy acrylate resins. Progress in Organic Coatings. 2002; 44(4):271-278. http://dx.doi.org/10.1016/S0300-9440(02)00059-0.
24. Choudhary V, Agarwal N and Varma IK. Evaluation of bisacrylate terminated epoxy resins as coatings. Progress in Organic Coatings. 2006; 57(3):223-228. http://dx.doi.org/10.1016/j. porgcoat.2006.09.004.

25. Tai HJ, Wang JB, Chen JH and Chou HL. Synthesis and properties of vinyl siloxane modified cresol novolac epoxy for electronic encapsulation. Journal of Applied Polymer Science. 2001; 79(4):652-661. http://dx.doi.org/10.1002/10974628(20010124)79:4<652::AID-APP90>3.0.CO;2-U.

26. Menon ARR, Aigbodion AI, Pillai CKS, Mathew NM and Bhagawan SS. Processability characteristics and physicomechanical properties of natural rubber modified with cashew nut shell liquid and cashew nut shell liquid-formaldehyde resin. European Polymer Journal. 2002; 38(1):163-168. http://dx.doi. org/10.1016/S0014-3057(01)00165-3.

27. Lin JM and Ma CCM. Thermal degradation of phenolic resin/ silica hybrid creamers. Polymer Degradation \& Stability. 2000; 69(2):229-235. http://dx.doi.org/10.1016/S0141-3910(00)00068-9.

28. Devi A and Srivastava D. Studies on the blends of cardanolbased epoxidized novolac resin and CTPB. European Polymer Journal. 2007; 43(6):2422-2432. http://dx.doi.org/10.1016/j. eurpolymj.2007.03.006.

29. Motawei AM, Badr MM, Amer MS, Mostafa HY and Ali IM. Some coating studies on phenolic epoxy/poly (Vinyl Acetate) $)_{5}$ resins. Journal of Applied Scientific Research. 2008; 4(9):1043-1051. 